\title{
Long-term outcomes of a pseudo 360-degree trabeculotomy ab externo technique for congenital glaucoma at children's medical center
}

This article was published in the following Dove Press journal:

Clinical Ophthalmology

8 May 2012

Number of times this article has been viewed

\section{Robert M Saltzmann \\ Steven Reinecke \\ Xihui Lin \\ H Dwight Cavanagh \\ Jess TWhitson}

University of Texas Southwestern

Medical Center, Department of

Ophthalmology, Dallas, TX, USA
Correspondence: Jess T Whitson 5323 Harry Hines Blvd, University of Texas Southwestern Medical Center, Department of Ophthalmology, Dallas, TX, USA

Tel +I 2146484733

Fax + I 2146482469

Email jess.whitson@utsouthwestern.edu
Purpose: To quantify the long-term outcomes of congenital glaucoma and surgical success rates following pseudo 360-degree trabeculotomy surgery at Children's Medical Center in Dallas.

Patients and methods: An International Classification of Diseases (ICD-9) database was utilized for a retrospective chart review. Thirty-eight eyes of 24 who underwent primary trabeculotomy with a pseudo 360-degree technique between June 1, 1992 and December 31, 2005 were studied.

Results: Mean age at the time of trabeculotomy was $11.1 \pm 3.0$ months, with seven eyes operated on after 1 year of age. Mean follow-up was $85.1 \pm 9.0$ months. Mean intraocular pressure (IOP) at the time of glaucoma diagnosis was $32.7 \pm 1.1 \mathrm{mmHg}$, and final mean IOP for all eyes (after trabeculotomy and any additional surgery and/or glaucoma medications) was $17.9 \pm 0.8 \mathrm{mmHg}$. With trabeculotomy and medication alone, mean final IOP was $19.9 \pm 1.1 \mathrm{mmHg}$, with a mean drop in IOP of $12.5 \pm 1.4 \mathrm{mmHg}$. Surgical success, defined by adequate IOP control, was achieved in 30 eyes (78.96\%) at most recent follow-up. Kaplan-Meier analysis demonstrated 5- and 10 -year survival probabilities of $93.1 \%$ and $66.8 \%$, respectively. Seventeen eyes $(44.7 \%$ of all eyes) achieved complete success, meaning IOP control $<21 \mathrm{mmHg}$ without additional medical therapy. All seventeen had primary congenital glaucoma (PCG); no eyes with aphakic glaucoma (AG) or Sturge-Weber syndrome (SWS) achieved complete success. Seven eyes (18.4\%) failed primary trabeculotomy. Mean time to failure was $46.9 \pm 8.6$ months. Eyes with SWS had a significantly higher failure rate $(P=0.009)$ and a 5.81 relative risk of failure $(P=0.026)$.

Conclusions: Our long-term trabeculotomy success rates for congenital glaucoma compare favorably with existing reports in the literature. Eyes with AG and SWS may warrant consideration of alternative primary surgical methods, or closer postoperative surveillance.

Keywords: congenital glaucoma, trabeculotomy, surgical outcome

\section{Introduction}

Primary congenital glaucoma (PCG) is a rare disease, occurring at a ratio of approximately $1: 10,000$ to $1: 20.000$ in newborns in Western countries, but it is responsible for $2.5 \%-15 \%$ of all documented cases of pediatric blindness. ${ }^{1-4}$ Primary congenital glaucoma due to isolated trabeculodysgenesis is the most common etiology of infantile glaucoma, but other conditions such as Axenfeld-Rieger anomaly, Peters' anomaly, Sturge-Weber syndrome, aphakia, aniridia, and uveitis may also result in secondary glaucoma. ${ }^{5}$

Therapy for congenital glaucoma is primarily surgical, and a number of different approaches have been proposed. Barkan first described goniotomy in 1942. ${ }^{6}$ Trabeculotomy was popularized by several authors ${ }^{7-10}$ including Harms and Dannheim in 1970. ${ }^{11}$ A modified 360-degree trabeculotomy technique using 
6-0 polypropylene suture (Prolene ${ }^{\circledR}$; Ethicon Inc, New Brunswick, NJ) was reported by Beck and Lynch in 1995, with high surgical success rates compared to conventional $\left(180^{\circ}\right)$ procedures. $^{12}$

The early literature centered on whether goniotomy or trabeculotomy is the better primary approach, and although each has its own advantages and shortcomings, these two methods are now felt to be roughly equivalent for controlling intraocular pressure (IOP), at least in the setting of a clear cornea. ${ }^{14-16}$ Nevertheless, Mendicino et al suggested that the 360-degree suture trabeculotomy technique may yield better visual outcomes than goniotomy. ${ }^{17}$

The reported long-term success rates of trabeculotomy have generally been high, but those numbers typically come from centers or individual surgeons with high volumes and experience. The number of reports evaluating long-term surgical outcomes, both with respect to congenital glaucoma in general and trabeculotomy in particular, is limited. ${ }^{18-22}$ For example, among 17 eyes of eleven patients undergoing primary trabeculotomy, Dietlein et al report success rates of $77 \%, 59 \%$, and $53 \%$ at 6 months, 2 years, and 5 years, respectively. ${ }^{18}$ Akimoto et al examined 116 eyes and cite 5- and 10-year surgical success rates of $62.9 \%$ and $51.5 \%$, respectively, for initial trabeculotomy, and total 5- and 10 -year success probabilities of $92.5 \%$ and $76.5 \%$, respectively, for one or more trabeculotomies. ${ }^{19}$ Similarly, Ikeda et al report 5- and 10- year success rates of $94.3 \%$ and $87.7 \%$, respectively, after the first trabeculotomy among 112 eyes with primary developmental glaucoma. ${ }^{22}$

Long-term outcome data from the United States remains sparse, and more recent reports tend to address newer and combined techniques. ${ }^{23-31}$ The purpose of this report is to analyze long-term outcomes for a pseudo 360-degree trabeculotomy technique, using conventional Harms probes, at Children's Medical Center in Dallas.

\section{Patients and methods}

This study was approved by the Institutional Review Boards of both the University of Texas Southwestern Medical Center and Children's Medical Center of Dallas (CMC) as a retrospective chart review. Charts were located through an International Statistical Classification of Diseases and Related Health Problems (ICD-9) and Current Procedural Terminology (CPT) database search at CMC, looking for patients/eyes that met the following criteria: (1) carried a diagnosis of congenital glaucoma, either in the medical record, or on the basis of ICD-9 coding for glaucoma of childhood (365.14); (2) had undergone trabeculotomy surgery
(CPT procedure code 65850) performed at CMC between June 1, 1992 and December 31, 2005.

After identifying patients/eyes based on these inclusion criteria, charts were manually reviewed and eyes were excluded based upon the following exclusion criteria: (1) trabeculotomy performed at another institution prior to referral to $\mathrm{CMC}$; (2) less than a minimum 1-year follow-up from the time of surgery to most recent examination; (3) presence of any comorbid congenital ocular pathologies, other than congenital or secondary glaucoma, that might affect the success of trabeculotomy surgery with respect to ultimate visual outcome (eg, persistent hyperplastic primary vitreous, retinopathy of prematurity, Coat's disease); (4) eyes with Peters' anomaly that underwent trabeculotomy but subsequently required corneal transplant within the first five years of follow-up - as the effects of secondary glaucoma after penetrating keratoplasty $(\mathrm{PK})$ cannot clearly be separated from primary failure of the trabeculotomy.

Syndromes and systemic disorders predisposing to congenital glaucoma (eg, Down syndrome, Turner syndrome, Lowe syndrome, Stickler syndrome, and Zellweger syndrome) were not specifically excluded. Likewise, strabismus and amblyopia alone were not considered criteria for exclusion. There were no sex, race, or other demographic criteria used for inclusion/exclusion.

The surgical technique employed in all cases begins in the superonasal quadrant with a 90-degree limbal peritomy; dissection of a partial thickness, limbus-based scleral flap (either triangular or trapezoidal); a radial cut-down to Schlemm's canal; rotation of Harms trabeculotomes in each direction through the trabecular meshwork and into the anterior chamber; maintenance of anterior chamber depth through injection of viscoelastic through a temporal paracentesis; closure of the scleral flap (typically with a 10-0 nylon suture); closure of the conjunctiva at the limbus (typically with $8-0$ vicryl); and repetition of the procedure in the inferotemporal quadrant, following rotation of the microscope 180 degrees away from the first position. In other words, two separate 120- to 180degree Harms trabeculotomies are performed simultaneously at the same sitting. We have dubbed this a "pseudo 360-degree" technique. At the conclusion of the procedure, subconjunctival injections of antibiotic and steroid are administered, and the eye is dressed with antibiotic or combination antibiotic-steroid ointment, followed by a patch and overnight shield. The postoperative treatment regimen includes topical antibiotic (typically a fluoroquinolone) four times daily for 1 week and prednisolone acetate, beginning at four times daily with a slow taper over approximately 6 weeks. 
Among eyes included for study, the following parameters were recorded: (1) etiology of glaucoma; (2) date of surgery; (3) age at the time of surgery; (4) nature of procedure and any intraoperative complications noted in the operative report; (5) total follow-up time between surgery and most recent examination; (6) any significant peri- and postoperative complications; (7) initial (eg, at the time of glaucoma diagnosis and/or examination under anesthesia with trabeculotomy), (8) final, and (9) net change in cup-to-disk ratio (C:D); (10) initial, (11) final, and (12) net change in IOP; (13) IOP just prior to any secondary surgical intervention; (14) corneal diameter, and (15) any change in corneal diameter throughout the course of follow-up; (16) total number and (17) type of medications required post trabeculotomy; (18) number, and (19) type of any secondary surgical interventions; (20) final visual acuity outcome, and (21) performance, on any visual field testing. Virtually all IOP and C:D data were recorded from examinations under anesthesia during the follow-up period (due to patient age). IOP was measured just after induction of general anesthesia using a hand-held Tono-Pen ${ }^{\circledR}$ XL applanation tonometer (Reichert Technologies, Depew, NY). For tabulation purposes, fixed-combination drops, such as dorzolamide-timolol, were counted as two drugs.

Failure of primary trabeculotomy was defined as persistent IOP $>30 \mathrm{mmHg}$ on two or more medications, or IOP $>30 \mathrm{mmHg}$ on less than two medications with sufficient $\mathrm{C}: \mathrm{D}$ progression to warrant additional surgical intervention. For the purpose of this analysis, cycloablation was considered surgical intervention, and thus grounds for failure. Complete surgical success was achieved if IOP $<21 \mathrm{mmHg}$ was maintained over the course of follow-up, without the need for additional medical therapy. Otherwise, surgery was deemed a partial (or incomplete) success. Corneal diameter measurements were inconsistent, and in no case was corneal diameter found to change by $\geq 1.0 \mathrm{~mm}$ over the course of follow-up. Therefore, change/progression in corneal diameter alone was not used as a criterion to determine surgical success.

Outcomes were then evaluated based upon surgical success, type of glaucoma, age at the time of surgery, and final visual outcome. Statistical analyses were performed using SigmaStat ${ }^{\circledR}\left(\right.$ Systat $^{\circledR}$ Software, Chicago, IL). Data is expressed as mean \pm standard error of the mean (SEM). Univariate statistical analysis was performed using one-way analysis of variance (ANOVA), with Holm-Sidak multiple comparisons, where applicable, or two-tailed Student's $t$-test for continuous data. Kruskal-Wallis one-way ANOVA on ranks was used if and when the normality test failed. Chi-squared, with Yates' correction, where applicable, or Fisher's exact test were used for normative data. Multivariate analysis was performed via two-way ANOVA. MedCalc v 9.5.2.0 (MedCalc Software, Mariakerke, Belgium) was used to generate Kaplan-Meier success probability curves for life table and survival probability analyses. A $P$ value of $<0.05$ was considered statistically significant.

\section{Results Study cohort}

The database query generated 36 patient charts for review. Of these, 21 eyes of twelve patients were excluded, as shown in Table 1. Thirty-eight eyes of 24 patients who underwent trabeculotomy between June 9, 1992 and November 22, 2005 were then included in the study. In 14 cases (58.3\%), bilateral trabeculotomies were performed, where both eyes met study criteria. All charts had operative reports available for review. No operative reports indicated any difficulty in locating Schlemm's canal and passing the Harms probes, or that any less than four passes of the probes (one in each direction at each of the two cut-down sites) were performed. Thirty-six of 38 eyes were operated on by the same primary surgeon.

Table 2 shows the baseline demographics of eyes in the study cohort, including sex, laterality, age at time of surgery, and mean follow-up time. Seven eyes were operated on after 1 year of age. Glaucoma subtypes are indicated in Figure 1. Of note, two patients with uncommon presentations of Sturge-Weber syndrome (SWS) with bilateral glaucoma were included.

\section{Surgical complications}

There were no documented complications attributed to the trabeculotomy. No eyes exhibited prolonged hyphema, hypotony, or choroidal effusions lasting beyond the first month postoperatively. One eye developed a vitreous hemorrhage, secondary to trauma that occurred in the first 2 months postoperatively, that cleared without surgical intervention.

\section{Surgical success analysis}

Mean IOP at the time of glaucoma diagnosis was $32.7 \pm 1.1 \mathrm{mmHg}$. Final IOP (after trabeculotomy, medication, and any additional surgical intervention) averaged $17.9 \pm 0.8 \mathrm{mmHg}$ at most

Table I Reasons for study exclusion

\begin{tabular}{ll}
\hline Trabeculotomy not performed at CMC & 7 patients ( 13 eyes) \\
Insufficient follow-up $(<$ I year) & 2 patients ( 2 eyes $)$ \\
Peters' anomaly with PK following trabeculotomy & I patient ( 2 eyes $)$ \\
Unable to locate chart & 2 patients \\
\hline
\end{tabular}


Table 2 Baseline demographics of study cohort

\begin{tabular}{ll}
\hline Gender & I3 M (54.2\%), II F (45.8\%) \\
Laterality & I 8 OD (47.4\%), 20 OS (52.6\%), I4 OU (58.3\%) \\
$\begin{array}{l}\text { Age at the time } \\
\text { of surgery }\end{array}$ & II.I \pm 3.0 months (range 0.3-I02.5 months) \\
Follow-up time & $85.1 \pm 9.0$ months (range 16.6-199.4 months) \\
\hline
\end{tabular}

Abbreviations: $M$, male; F, female; OD, left eye; OS, right eye; OU, both eyes.

recent follow-up. With trabeculotomy and medication alone, mean postoperative IOP was $19.9 \pm 1.1 \mathrm{mmHg}$, with a mean drop in IOP of $12.5 \pm 1.4 \mathrm{mmHg}$.

Prostaglandin analogues were the most common agents used for IOP control, followed by carbonic anhydrase inhibitors and beta-blockers. Surgical success, defined by sufficient IOP control with primary trabeculotomy and medication alone, was achieved in 30 eyes (78.96\%). One eye, with a final IOP of $25 \mathrm{mmHg}$, on monotherapy, and subsequently lost to follow-up, could not adequately be labeled as either a success or failure. No other eyes fell into this intermediate zone, with IOP in the 21-30 range. Seventeen eyes $(44.7 \%$ of all eyes; $56.7 \%$ of successful eyes) achieved complete success. Among eyes with partial surgical success, mean time to initiate medical therapy was $15.5 \pm 6.9$ months postoperatively. The mean number of medications at last follow-up was $1.4 \pm 0.2$.

Seven eyes (18.4\%) in five patients failed primary trabeculotomy, six based upon a postoperative IOP $>30 \mathrm{mmHg}$ on two or more medications, and one based upon a $\mathrm{C}: \mathrm{D}$ ratio of 0.95 , and persistent $\mathrm{IOP}>30 \mathrm{mmHg}$ at 3 months postoperatively, prompting additional intervention. Mean time to failure was $46.9 \pm 8.6$ months postoperatively (range 11.7-66.9 months). Among those who failed primary trabeculotomy, $1.6 \pm 0.5$ additional surgeries (range $0-3)$ were performed. Table 3 lists the secondary surgeries performed on eyes in the failure group. Of note, the parents of one patient with bilateral failure, and documented poor compliance with medical therapy, declined any further intervention, and there are no current plans for additional surgery.

Among the 14 patients in whom both eyes were included in the study, nine (64.3\%) achieved bilateral surgical success, and two (14.3\%) had bilateral failure. As discussed below, both of these patients represented uncommon presentations of SWS with bilateral glaucoma, and both demonstrated poor compliance with medical therapy. Of the nine patients with bilateral surgical success, seven $(77.8 \%)$ had complete success in both eyes. Three patients $(21.4 \%)$ had one eye that failed and one that had partial success.

Eyes that achieved surgical success, and those that failed, are compared, using multiple parameters, in Table 4. Similarly, complete and incomplete successes are compared in Table 5 . The final C:D ratio was significantly higher among eyes that failed surgery, compared to those that achieved surgical success $(0.71 \pm 0.08$ vs $0.47 \pm 0.04 ; P=0.018)$. Eyes that failed surgery had a mean increase in $\mathrm{C}: \mathrm{D}$ ratio $(0.13 \pm 0.07)$ over the course of follow-up, which compares to a mean decrease in $\mathrm{C}$ : $\mathrm{D}$ ratio $(-0.10 \pm 0.04)$ among those which achieved surgical success $(P=0.007)$. Similarly, eyes achieving complete success had lower mean C:D ratios $(0.36 \pm 0.03$ vs $0.61 \pm 0.56 ; P<0.001)$ and less $\mathrm{C}: \mathrm{D}$ ratio progression $(-0.16 \pm 0.04$ vs $0.01 \pm 0.06 ; P=0.028)$ than those with incomplete success. By definition, IOP on medication alone was higher in the failure group $(P<0.001)$, as was the IOP response to medication alone among the surgical success group $(P<0.001)$. There were no differences in initial C:D ratio, initial IOP, corneal diameter, age at trabeculotomy, or follow-up time, either with respect to success vs failure, or complete vs incomplete success. Although no eyes operated on after 12 months of age went on to achieve complete success, there was no difference in failure rates between infantile and older eyes $(P=0.608)$.

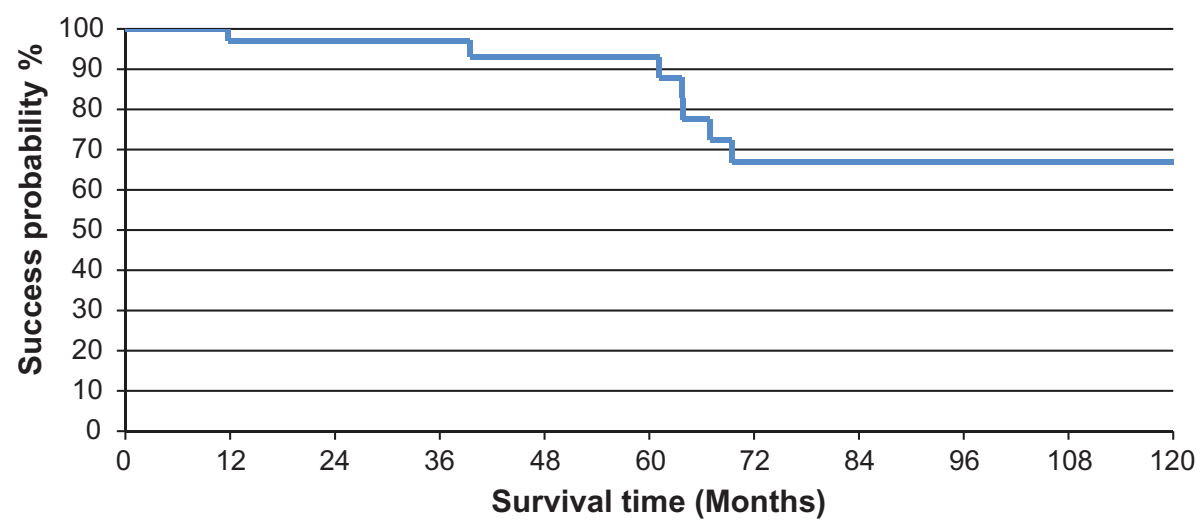

Figure I Kaplan-Meier success probability survival curve for primary trabeculotomy at CMC. Note: Trabeculotomy was performed at the Children's Medical Center, Dallas, TX. 
Table 3 Secondary surgeries among eyes that failed primary trabeculotomy

\begin{tabular}{|c|c|c|c|}
\hline Eye & Patient & No surgeries & Secondary surgeries \\
\hline I & 1 & 3 & Cyclocryo therapy $\times 3$ \\
\hline 2 & 2 & 2 & Cyclodiode, Ahmed tube shunt \\
\hline 3 & 3 & 3 & $\begin{array}{l}\text { Cyclodiode, Baerveldt tube } \\
\text { shunt, cyclodiode }\end{array}$ \\
\hline 4 & 4 & 2 & Ahmed tube shunt, cyclodiode \\
\hline 5 & & 2 & Ahmed tube shunt, cyclodiode \\
\hline
\end{tabular}

Kaplan-Meier survival curve analysis was performed and is shown in Figure 2. Accompanying life table analysis is shown in Table 6. Five- and 10-year survival probabilities for primary trabeculotomy were $93.1 \% \pm 0.05 \%$ and $66.8 \% \pm 0.11 \%$, respectively.

Among surgical successes, 5- and 10-year survival rates for complete success were $55.9 \% \pm 0.1 \%$ and $46.6 \% \pm 0.1 \%$, respectively, as shown in Figure 3 (life table analysis not shown).

\section{Outcomes by glaucoma etiology}

For the purpose of data analysis, the eye with Rieger anomaly was grouped with the SWS eyes under the rubric of "secondary glaucomas due to ocular anomalies". Comparisons between multiple parameters are shown in Table 7. The proportion of eyes with secondary glaucoma that went on to fail was significantly higher than those with congenital or aphakic glaucoma $(P=0.009)$. They were also less likely to achieve complete success $(P=0.02)$. Additionally, these eyes

Table 4 Comparison of surgical success vs failure

\begin{tabular}{|c|c|c|c|}
\hline Variable & Success & Failure & $P$ \\
\hline $\mathrm{n}(\%)$ & 30 (78.95\%) & 7 (I8.4\%) & \\
\hline $\begin{array}{l}\text { Age at TAE } \\
\text { (months) }\end{array}$ & $11.79 \pm 3.84$ & $9.37 \pm 3.81$ & 0.469 \\
\hline $\begin{array}{l}\text { Follow-up } \\
\text { (months) }\end{array}$ & $80.41 \pm 10.72$ & $93.28 \pm 14.63$ & 0.257 \\
\hline Initial C:D & $0.55 \pm 0.04$ & $0.58 \pm 0.08$ & 0.742 \\
\hline Final C:D & $0.47 \pm 0.04$ & $0.7 I \pm 0.08$ & $0.018 *$ \\
\hline$\Delta \mathrm{C}: \mathrm{D}$ & $-0.10 \pm 0.04$ & $+0.13 \pm 0.07$ & $0.007 *$ \\
\hline Initial IOP (mmHg) & $32.16 \pm 1.06$ & $36.14 \pm 2.76$ & 0.124 \\
\hline Final IOP $(\mathrm{mmHg})$ & $16.63 \pm 0.50$ & $23.57 \pm 3.54$ & 0.126 \\
\hline $\begin{array}{l}\text { IOP meds alone } \\
(\mathrm{mmHg})\end{array}$ & $16.63 \pm 0.50$ & $33.21 \pm 0.62$ & $<0.00 I^{*}$ \\
\hline$\Delta \mathrm{IOP}$ net $(\mathrm{mmHg})$ & $-15.59 \pm 1.12$ & $-12.57 \pm 4.55$ & 0.509 \\
\hline $\begin{array}{l}\Delta \mathrm{IOP} \text { meds alone } \\
(\mathrm{mmHg})\end{array}$ & $-15.59 \pm 1.12$ & $-2.93 \pm 2.61$ & $<0.00 I^{*}$ \\
\hline $\begin{array}{l}\text { Corneal diameter } \\
(\mathrm{mm})\end{array}$ & $13.36 \pm 0.34$ & $13.15 \pm 0.17$ & 0.570 \\
\hline No medications & $0.60 \pm 0.16$ & $1.43 \pm 0.37$ & 0.065 \\
\hline
\end{tabular}

Notes: $* P<0.05$ was considered statistically significant.

Abbreviations: TAE, trabeculotomy ab externo; C:D, cup-to-disk ratio; IOP, intraocular pressure.
Table 5 Comparison of complete vs incomplete surgical success

\begin{tabular}{|c|c|c|c|}
\hline Variable & Complete & Incomplete & $P$ \\
\hline n (\%) & 17 (56.7\%) & $13(43.3 \%)$ & \\
\hline Age at TAE (months) & $11.79 \pm 3.84$ & $9.37 \pm 3.81$ & 0.469 \\
\hline Follow-up (months) & $71.74 \pm 12.69$ & $90.41 \pm 18.02$ & $0.38 \mathrm{I}$ \\
\hline Initial C:D & $0.54 \pm 0.06$ & $0.57 \pm 0.06$ & 0.678 \\
\hline Final C:D & $0.36 \pm 0.03$ & $0.61 \pm 0.56$ & $<0.00$ I* \\
\hline$\Delta \mathrm{C}: \mathrm{D}$ & $-0.16 \pm 0.04$ & $+0.01 \pm 0.07$ & $0.028 *$ \\
\hline Initial IOP (mmHg) & $32.07 \pm 1.67$ & $32.27 \pm 1.32$ & 0.926 \\
\hline Final IOP $(\mathrm{mmHg})$ & $16.12 \pm 0.59$ & $|7.3| \pm 0.84$ & 0.245 \\
\hline$\Delta \mathrm{IOP}(\mathrm{mmHg})$ & $-16.13 \pm 1.66$ & $-14.96 \pm 1.53$ & 0.612 \\
\hline Corneal diameter $(\mathrm{mm})$ & $13.38 \pm 0.22$ & $|2.9| \pm 0.24$ & 0.148 \\
\hline
\end{tabular}

Notes: $* P<0.05$ was considered statistically significant.

Abbreviations: TAE, trabeculotomy ab externo; C:D, cup-to-disk ratio; IOP, intraocular pressure.

were more likely to demonstrate C:D progression, higher IOP, and less IOP response to treatment. As a consequence, they required more medications by the time of most recent followup. In all cases where a statistically significant difference between groups was found, the difference was attributable to the difference between the congenital glaucoma group and those with SWS. There were no differences in age at the time of trabeculotomy, the initial or final C:D ratio, initial IOP, corneal diameter, number of secondary surgeries, or total follow-up time.

Kaplan-Meier survival curves by glaucoma type are shown in Figure 4. Cox proportional hazards regression analysis suggests an instantaneous relative risk of failure of 5.81 (95\% confidence interval: $1.24-27.26 ; P=0.026$ ) associated with anomalous secondary glaucoma (SWS or Rieger anomaly), as compared with congenital glaucoma or aphakic glaucoma.

Multivariate analysis with two-way ANOVA demonstrated a statistically significant interaction between success and glaucoma type with respect to final IOP $(P<0.001)$ and response to IOP on medications alone $(P=0.038)$. Hence, the differences noted in Table 4 , between success and failure among these two parameters, could be explained by differences in glaucoma type: the disproportionate tendency for eyes in the Sturge-Weber/Rieger group to fail primary trabeculotomy.

\section{Compliance with follow-up}

After noting that four of seven surgical failures were generated from only two patients with bilateral SWS-related glaucoma, we suspected that poor compliance with medication and/or follow-up may have played a role in those outcomes. Using average number of follow-up visits per year as a surrogate for compliance, no statistically significant relationships were identified between follow-up rates and outcomes 


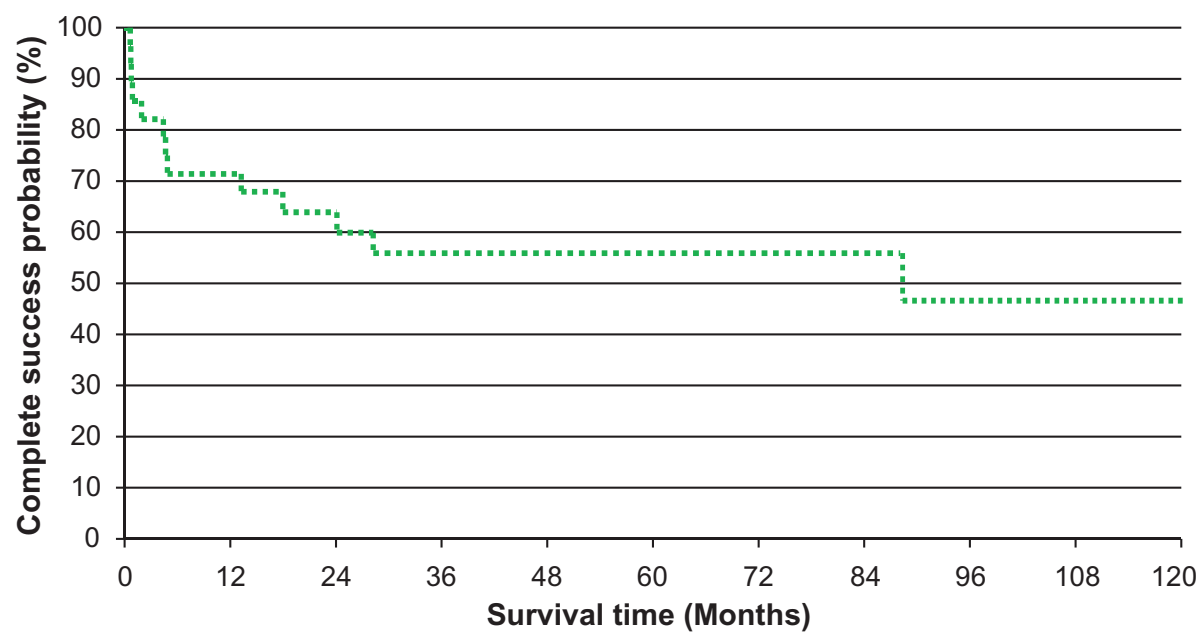

Figure 2 Kaplan-Meier curve for complete success.

(success vs failure), when analyzed across several time periods (see Table 8). However, eyes that achieved complete success ultimately required slightly fewer follow-up visits per year after the first postoperative year than those with incomplete success. Although some of these patients were also followed-up separately by the general pediatric ophthalmology team for ongoing treatment of amblyopia, strabismus, and other comorbid ocular conditions, only scheduled follow-up appointments with our glaucoma specialist were considered in this analysis.

We then looked specifically at the same measurements in eyes with SWS compared to those with PCG. Eyes with SWS had significantly fewer follow-up visits in the first postoperative year (Table 9). Assessment of follow-up in the SWS cohort was limited after 5 years postoperatively, as only one eye had follow-up extending to 10 years, and that patient returned at year 10, after 4 years without follow-up.

Table 6 Life table analysis

\begin{tabular}{llllc}
\hline $\begin{array}{l}\text { Follow-up } \\
\text { (months) }\end{array}$ & $\begin{array}{l}\text { No eyes } \\
\text { at risk }\end{array}$ & No failures & $\begin{array}{l}\text { No lost to } \\
\text { follow-up }\end{array}$ & $\begin{array}{l}\text { Survival } \\
\text { proportion } \\
\text { (\% } \pm \text { SE) }\end{array}$ \\
\hline 6 & 35 & 0 & 0 & $100 \pm 0.0$ \\
12 & 34 & 1 & 0 & $97.1 \pm 0.03$ \\
24 & 32 & 0 & 2 & $97.1 \pm 0.03$ \\
36 & 26 & 0 & 6 & $97.1 \pm 0.03$ \\
48 & 20 & 1 & 5 & $93.1 \pm 0.05$ \\
60 & 19 & 0 & 1 & $93.1 \pm 0.05$ \\
72 & 12 & 5 & 2 & $66.8 \pm 0.11$ \\
84 & 10 & 0 & 2 & $66.8 \pm 0.11$ \\
96 & 10 & 0 & 0 & $66.8 \pm 0.11$ \\
108 & 10 & 0 & 0 & $66.8 \pm 0.11$ \\
120 & 7 & 0 & 3 & $66.8 \pm 0.11$ \\
\hline
\end{tabular}

Abbreviation: SE, standard error.

\section{Final visual outcomes}

Lastly, an attempt was made to evaluate functional surgical outcomes based upon final visual acuity and performance using automated Humphrey visual field testing. Snellen acuities were able to be quantified in 27 of 38 eyes $(71.1 \%)$. Of the remaining eleven eyes, two were deemed to have amblyopia, based upon poor maintenance of fixation, and two had marked nystagmus, in one patient with Down syndrome and aphakia. All four of these eyes were incomplete surgical successes. The remainder were evaluated by the central, steady, maintained (CSM) conventional nomenclature, and were found to be normal on all three parameters. Among the eleven eyes, eight had congenital glaucoma, and three had aphakic glaucoma. The number of eyes in this group was too small to derive any meaningful relationships.

The 27 eyes in which a final Snellen best-corrected visual acuity score could be obtained were stratified into three visual outcome groups: 20/20-20/40, 20/50-20/200, and $\leq 20 / 400$. These three groups were compared along multiple parameters, as shown in Table 10.

Those eyes with poor visual outcomes $\leq 20 / 400$ were found to have significantly higher initial C:D $(P=0.028)$, final C:D ratio $(P=0.005)$, and corneal diameter $(P=0.043)$, compared to the other two groups. They also exhibited a much larger decrease in IOP from the time of trabeculotomy to the most recent follow-up $(P=0.03)$. There were no differences between the groups with respect to age at trabeculotomy, follow-up time, initial or final IOP, number of medications required in the postoperative period, proportion of surgical success vs failure, or distribution of glaucoma subtypes within each. 


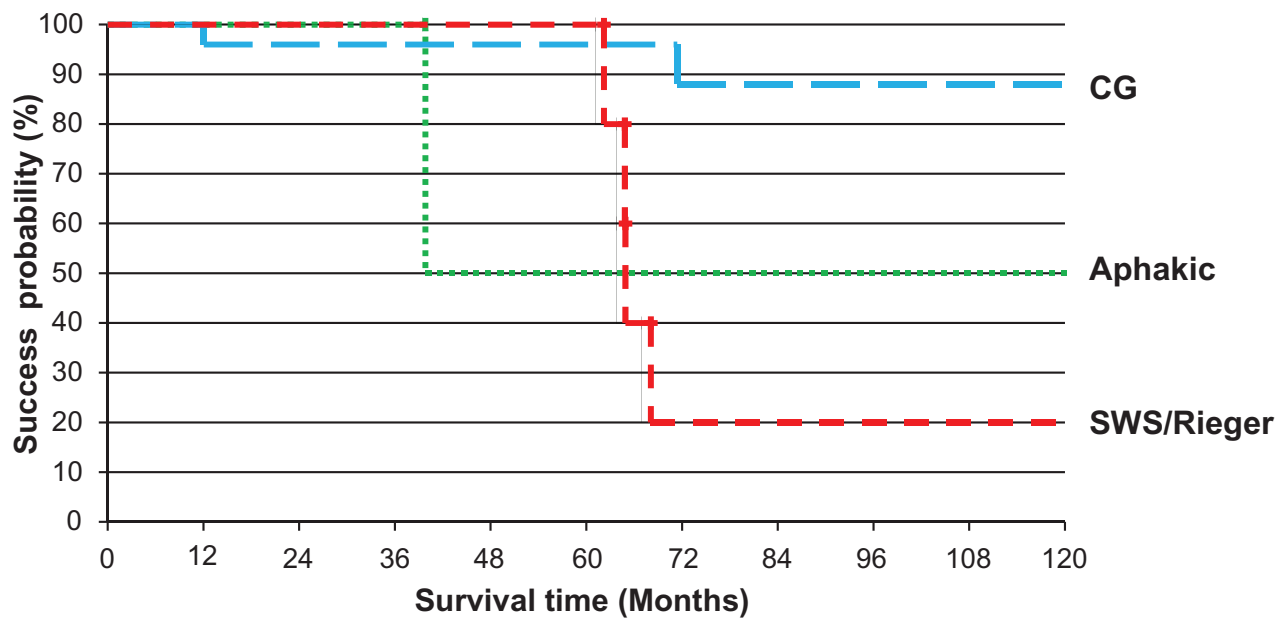

Figure 3 Kaplan-Meier success probability curves by type of glaucoma. Abbreviations: CG, Congenital Glaucoma; SWS, Sturge-Weber Syndrome.

Unilaterally affected cases were also examined, given the increased risk of amblyopia in these eyes. Of the 27 eyes with available Snellen acuity data, nine had unilateral glaucoma. Of those, five (56\%) were $20 / 40$ or better, and four (44.4\%) were $20 / 25$ or $20 / 20$ at most recent follow-up. Two eyes $(22.2 \%)$ were in the poorest visual outcome $(\leq 20 / 400)$ group.

\section{Discussion}

Pediatric glaucoma remains a challenging problem for the ophthalmologist. Eyes with this disorder often require a combination of medications and surgery for optimal IOP control.
At our medical center, primary trabeculotomy, using a traditional Harms' probe for pediatric glaucoma, provides respectable surgical success rates: $78.95 \%$ overall; $93.1 \pm 0.05 \%$ at 5 years, and $66.8 \pm 0.11 \%$ at 10 years. Moreover, $56.7 \%$ of those who achieved success required no additional medical therapy to maintain IOP at acceptable levels. In addressing a wider degree of the trabecular dysgenesis than a standard 180-degree procedure, our pseudo 360-degree technique may have accounted for these outcomes. This technique compares well with the $85 \%-92 \%$ success rates at 3-4 years reported for a 360-degree trabeculotomy with a 6-0 Prolene suture, ${ }^{12,17}$ as well as for those reported for combined trabeculotomy/trabeculectomy. ${ }^{25-30}$

Table 7 Comparison of outcomes by glaucoma type

\begin{tabular}{|c|c|c|c|c|}
\hline & PCG & $\begin{array}{l}\text { Anomalies } \\
\text { (SWS and AR) }\end{array}$ & Aphakic & $P$ \\
\hline n (\%) & 27 (7I. I\%) & 7 (I8.4\%) & $4(10.5 \%)$ & \\
\hline Age at TAE (months) & $12.46 \pm 4.14$ & $10.17 \pm 4.77$ & $4.82 \pm 0.28$ & 0.502 \\
\hline Follow-up (months) & $86.1 \pm 11.77$ & $86.97 \pm 14.40$ & $75.7 \pm 29.15$ & 0.758 \\
\hline Initial C:D & $0.58 \pm 0.05$ & $0.54 \pm 0.04$ & $0.47 \pm 0.09$ & 0.629 \\
\hline Final C:D & $0.50 \pm 0.04$ & $0.67 \pm 0.06$ & $0.44 \pm 0.11$ & 0.085 \\
\hline$\Delta \mathrm{C} / \mathrm{D}$ & $-0.01 \pm 0.04$ & $0.14 \pm 0.08$ & $-0.02 \pm 0.1$ & $0.023 *$ \\
\hline Initial IOP (mmHg) & $32.48 \pm 1.17$ & $32.14 \pm 2.68$ & $36.63 \pm 5.42$ & 0.936 \\
\hline Final IOP (mmHg) & $15.96 \pm 0.52$ & $25.14 \pm 2.88$ & $20.5 \pm 1.66$ & $0.003 *$ \\
\hline IOP meds alone $(\mathrm{mmHg})$ & $17.59 \pm 1.03$ & $26.36 \pm 3.24$ & $24.25 \pm 3.25$ & $0.003 *$ \\
\hline$\Delta \mathrm{IOP}$ net $(\mathrm{mmHg})$ & $-16.64 \pm 1.29$ & $-7.0 \pm 2.44$ & $-13.13 \pm 6.96$ & $0.017 *$ \\
\hline$\Delta \mathrm{IOP}$ meds alone $(\mathrm{mmHg})$ & $-14.88 \pm 1.45$ & $-5.79 \pm 2.97$ & $-9.38 \pm 5.73$ & $0.027 *$ \\
\hline Corneal diameter (mm) & $13.33 \pm 0.18$ & $12.83 \pm 0.17$ & $12.5 \pm 0.5$ & 0.102 \\
\hline No medications & $0.4 \pm 0.15$ & $1.86 \pm 0.26$ & $1.50 \pm 0.29$ & $<0.00 I^{*}$ \\
\hline No surgeries & $0.2 \pm 0.14$ & $0.71 \pm 0.47$ & $0.25 \pm 0.25$ & 0.28 \\
\hline Failures & $2(7.4 \%)$ & $4(57.1 \%)$ & I (25\%) & $0.009 *$ \\
\hline Success & $25(92.6 \%)$ & $3(42.9 \%)$ & $2(50 \%)$ & \\
\hline Complete success & 17 (68\%) & $0(0 \%)$ & $0(0 \%)$ & $0.02 *$ \\
\hline Incomplete success & $8(32 \%)$ & $3(100 \%)$ & $2(100 \%)$ & \\
\hline
\end{tabular}

Notes: $* P<0.05$ was considered statistically significant.

Abbreviations: TAE, trabeculotomy ab externo; C:D, cup-to-disk ratio; IOP, intraocular pressure; SWS, Sturge-Weber syndrome; AR, Axenfeld-Rieger anomaly. 


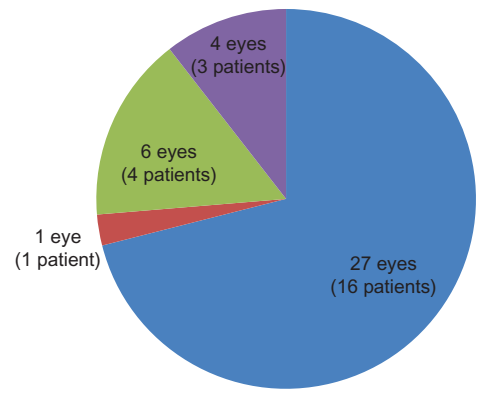

Primary congenital

glaucoma

- Rieger's anomaly

- Sturge-Weber syndrome

- Aphakic glaucoma

Figure 4 Glaucoma subtype among study eyes.

This retrospective outcome review also highlights a disparity in response to primary trabeculotomy between glaucoma subgroups. Eyes with SWS had a much more limited response, with a higher failure rate and relative risk of failure of 5.81, more C:D progression, higher IOP (both on medication alone and after additional surgical interventions), and less IOP response to treatment. As a consequence, these eyes required significantly more medications by the time of most recent follow-up. While our series has a limited number of cases of SWS, our findings are comparable with results from larger series of eyes with SWS, as have been reported in the literature. ${ }^{22}$ It has been hypothesized that the pathophysiology of Sturge-Weber syndrome - elevated episcleral venous pressure downstream to Schlemm's canal in the aqueous outflow pathway - may render such eyes less amenable to modification of the trabecular meshwork (ie, goniotomy/ trabeculotomy) as a surgical remedy for glaucoma. ${ }^{22,32-36}$ In concert with our findings, Ikeda et al also found that eyes with secondary glaucomas have lower success probabilities at 5,10 , and 15 years, than those with primary developmental glaucoma, after trabeculotomies $(82.2 \%$ vs $94.3 \%$ at 5 years, $77.1 \%$ vs $87.7 \%$ at 10 years, and $64.2 \%$ vs $80.8 \%$ at 20 years). ${ }^{22}$ Furthermore, eyes with SWS fared the worst among those with secondary glaucomas, yielding the lowest success rates, highest mean IOPs, and largest proportion of eyes with poor visual acuity $(<20 / 200){ }^{22}$

Table 8 Mean follow-up visits per year vs outcome

\begin{tabular}{lllll}
\hline & \multicolumn{2}{l}{ Success } & Failure & $\boldsymbol{P}$ \\
\cline { 2 - 3 } & Complete & Incomplete & & \\
\hline Year I & $3.0 \pm 0.2$ & & $2.3 \pm 0.5$ & 0.08 \\
Years I-5 & $2.8 \pm 0.2$ & $3.2 \pm 0.3$ & & 0.22 \\
& $1.6 \pm 0.4$ & & $1.2 \pm 0.3$ & 0.37 \\
Years 2-most & $1.3 \pm 0.4$ & $1.9 \pm 0.4$ & & 0.29 \\
recent exam & $0.8 \pm 0.1$ & $1.2 \pm 0.1$ & & 0.91 \\
Duration of & $1.2 \pm 0.2$ & & $1.3 \pm 0.3$ & 0.70 \\
follow-up & $0.9 \pm 0.2$ & $1.3 \pm 0.2$ & & 0.10 \\
\hline
\end{tabular}

Table 9 Mean follow-up visits per year, by glaucoma subtype

\begin{tabular}{llll}
\hline & $\begin{array}{l}\text { PCG } \\
(\mathbf{n}=\mathbf{2 7})\end{array}$ & $\begin{array}{l}\text { SWS } \\
(\mathbf{n}=\mathbf{6})\end{array}$ & $\boldsymbol{P}$ \\
\hline Year I & $3.0 \pm 0.2$ & $1.7 \pm 0.4$ & 0.001 \\
Years I-5 & $1.6 \pm 0.4$ & $1.0 \pm 0.2$ & 0.25 \\
Years 2-5 & $1.2 \pm 0.2$ & $0.9 \pm 0.2$ & 0.18 \\
Duration of follow-up & $\mathrm{I} . \mathrm{I} \pm 0.2$ & $1.1 \pm 0.2$ & 0.98 \\
\hline Abbreviations: PCG Primary Congental Glaura
\end{tabular}

Standard trabeculectomy, or combined trabeculotomy/ trabeculectomy, may be advantageous in SWS, bypassing Schlemm's canal and redirecting aqueous to the subconjunctival space. ${ }^{35-39}$ However, filtering surgery in the pediatric population is less likely to succeed. due to lower scleral rigidity and a rapid, often exuberant, healing response. ${ }^{40}$ Furthermore, the risk of complications, including expulsive hemorrhage, may be magnified in patients with SWS..$^{39,41}$

Ethnicity may influence surgical success for congenital glaucoma. Elder found a 5-year success rate of $35 \%$ when trabeculotomy was performed on Palestinian Arab children by general ophthalmologists. ${ }^{42}$ When performed by a specialist in the Middle East, Debnath et al reported a higher, but still modest, 1-year success rate of only $67 \% .{ }^{23}$ At their center in Ankara, Turkey, Yalvac et al reported better 12-, 24-, and 36 -month trabeculotomy success rates of $92 \%, 82 \%$, and $74 \%$, respectively, on eyes operated on within 3 months of birth. ${ }^{43} \mathrm{Al}$-Hazmi et al suggest that success may be related to glaucoma severity (based upon IOP, corneal diameter, and corneal clarity). ${ }^{44}$ In their series from Saudi Arabia, they found a marginal $41 \%$ overall success rate for trabeculotomy among 418 eyes, but a $93 \%$ success rate among the 102 eyes substratified as having mild glaucoma. There was a $65 \%$ success rate among eyes with moderate glaucoma, and only a $15 \%$ success rate among those with severe glaucoma. In our series, glaucoma severity was not categorized as such, and there was no attempt made to stratify or compare patients by ethnicity.

Despite the achievement of surgical success with respect to IOP control (as it is traditionally defined), the visual prognosis of patients with developmental glaucoma continues to be poor, with most reports indicating that less than half of these children achieve a final visual acuity of 20/50 or better. ${ }^{20,21,29}$ This discrepancy highlights the confounding effect of amblyopia in pediatric glaucomas. In our series, 13 of 38 eyes (34.2\%), representing 48.1\% (13/27) of eyes with quantifiable Snellen acuity, achieved 20/40 or better, which is in concert with previous reports. Among eyes with unilateral glaucoma, which may be those most prone to amblyopia, $56 \%$ achieved a visual acuity of 20/40 or better at most recent follow-up. 
Table 10 Comparison of outcomes by final visual acuity

\begin{tabular}{|c|c|c|c|c|}
\hline & $>20 / 40$ & $20 / 50-20 / 200$ & $\leq 20 / 400$ & $P$ \\
\hline n (\%) & $13(48.1 \%)$ & II (40.7\%) & $3(11.1 \%)$ & \\
\hline Age at TAE (months) & $12.24 \pm 3.97$ & $5.59 \pm 1.27$ & $46.73 \pm 28.53$ & 0.064 \\
\hline Follow-up (months) & $115.79 \pm 15.42$ & $98.56 \pm 15.18$ & $108.04 \pm 34.3$ & 0.739 \\
\hline Initial C:D & $0.46 \pm 0.04$ & $0.62 \pm 0.06$ & $0.75 \pm 0.18$ & $0.028 *$ \\
\hline Final C:D & $0.47 \pm 0.06$ & $0.59 \pm 0.05$ & $0.91 \pm 0.06$ & $0.005 *$ \\
\hline$\Delta \mathrm{C}: \mathrm{D}$ & $0.004 \pm 0.04$ & $-0.03 \pm 0.08$ & $0.16 \pm 0.12$ & 0.348 \\
\hline Initial IOP $(\mathrm{mmHg})$ & $31.55 \pm 1.78$ & $29.64 \pm 1.97$ & $38 \pm 4.04$ & 0.305 \\
\hline Final IOP (mmHg) & $18.96 \pm 1.73$ & $18.95 \pm 2.09$ & $13.0 \pm 1.0$ & 0.138 \\
\hline IOP meds alone (mmHg) & $|9.46 \pm 2.0|$ & $21.05 \pm 2.38$ & $20.67 \pm 7.22$ & 0.938 \\
\hline$\Delta \mathrm{IOP}(\mathrm{mmHg})$ & $-12.32 \pm 1.64$ & $-10.68 \pm 2.95$ & $-25.0 \pm 3.5 I$ & $0.03 *$ \\
\hline$\Delta \mathrm{IOP}$ meds alone $(\mathrm{mmHg})$ & $-11.73 \pm 2.08$ & $-8.59 \pm 3.13$ & $-17.33 \pm 6.36$ & 0.33 \\
\hline Corneal diameter $(\mathrm{mm})$ & $13.06 \pm 0.24$ & $12.58 \pm 0.2$ & $14.5 \pm 0.5$ & $0.043 *$ \\
\hline No medications & $\mathrm{I} .08 \pm 0.3 \mathrm{I}$ & $0.55 \pm 0.25$ & $I \pm I$ & 0.43 \\
\hline No surgeries & $0.15 \pm 0.15$ & $0.45 \pm 0.31$ & $0.67 \pm 0.6$ & 0.432 \\
\hline Failures & 2 & 3 & 1 & 0.644 \\
\hline Success & 11 & 7 & 2 & \\
\hline Incomplete success & 6 & I & 2 & 0.151 \\
\hline Complete success & 5 & 6 & 0 & \\
\hline \multicolumn{5}{|l|}{ Type of glaucoma } \\
\hline CG & 8 & 8 & 3 & 0.291 \\
\hline SWS/AR & 5 & I & 0 & \\
\hline Aphakic & 0 & I & 0 & \\
\hline
\end{tabular}

Notes: $* P<0.05$ was considered statistically significant.

Abbreviations: TAE, trabeculotomy ab externo; C:D, cup-to-disk ratio; IOP, intraocular pressure; CG, congenital glaucoma; SWS/AR, Sturge-Weber syndrome/ Axenfeld-Rieger anomaly.

The differences found within the $\leq 20 / 400$ visual acuity group were consistent with more aggressive and advanced glaucoma, indicated by higher initial and final C:D ratios and corneal diameters. Indeed, poor final visual acuity was the only outcome measure found to have any association with findings at initial glaucoma diagnosis, namely, C:D ratio. Initial IOP had no correlation with surgical success, glaucoma type, or visual outcome. The net decrease in IOP was also found to be higher within this group, likely reflecting more aggressive secondary surgical management, as evidenced by the fact that (1) initial IOPs were no higher in this group than the others, (2) the number of surgeries performed in this group was no higher, and (3) these eyes had a similar IOP response on medications alone (prior to any secondary surgery) compared to the other two visual outcome groups. Ultimately, there was no direct correlation between surgical success and the central visual acuity achieved.

Our study has several limitations, in particular, its retrospective design, the relatively small sample size, and the inconsistent availability of data for all variables across all study eyes. As with previous reports, outcomes in this study cohort suggest that eyes with aphakic glaucoma and Sturge-Weber syndrome may warrant consideration of alternative primary surgical methods, or closer postoperative surveillance. Overall, however, this review demonstrates that primary trabeculotomy with our technique compares favorably with those reported in the literature. Further studies are needed to determine the most effective and safest way to treat this uncommon but often devastating disease.

\section{Conclusions}

Our long-term trabeculotomy success rates for congenital glaucoma compare favorably with existing reports in the literature. Eyes with AG and SWS may warrant consideration of alternative primary surgical methods, or closer postoperative surveillance.

\section{Acknowledgments}

This study was supported, in part, by an unrestricted research grant from Research to Prevent Blindness, Inc, New York, New York, USA.

\section{Disclosure}

The authors report no conflicts of interest in this work.

\section{References}

1. Biglan AW. Glaucoma in children: are we making progress? J AAPOS. 2006;10:7-21.

2. Grehn F. Congenital glaucoma surgery: a neglected field in ophthalmology? Br J Ophthalmol. 2008;92:1-2. 
3. Yalvac IS, Satana B, Suveren A, et al. Success of trabeculotomy in patients with congenital glaucoma operated on within 3 months of birth. Eye. 2007;21:459-464.

4. DeLuise VP, Anderson DR. Primary infantile glaucoma (congenital glaucoma). Surv Ophthalmol. 1983;28:1-19.

5. Papadopoulos M, Khaw PT. Advances in the management of paediatric glaucoma. Eye. 2007;21:1319-1325.

6. Barkan O. Operation for congenital glaucoma. Am J Ophthalmol. 1942;25:552-568.

7. Smith R. A new technique for opening the canal of Schlemm. Preliminary report. Br J Ophthalmol. 1960;44:370-373.

8. Smith R. Nylon filament trabeculotomy in glaucoma. Trans Ophthalmol Soc UK. 1962;82:439-454.

9. Burian HM. A case of Marfan's syndrome with bilateral glaucoma. With description of a new type of operation for developmental glaucoma (trabeculotomy ab externo). Am J Ophthalmol. 1960;50:1187-1192.

10. Allen L, Burian HM. Trabeculotomy ab externo. A new glaucoma operation: technique and results of experimental surgery. Am J Ophthalmol. 1962;53:19-26

11. Harms H, Dannheim R. Epicritical consideration of 300 cases of trabeculotomy ab externo. Trans Ophthalmol Soc U K. 1970;89:491-494.

12. Beck AD, Lynch MG. 360 degrees trabeculotomy for primary congenital glaucoma. Arch Ophthalmol. 1995;113:1200-1202.

13. Filous A, Brunova B. Results of the modified trabeculotomy in the treatment of primary congenital glaucoma. J AAPOS. 2002;6(3):182-186.

14. Anderson DR. Trabeculotomy compared to goniotomy for glaucoma in children. Ophthalmology. 1983;90:805-806.

15. Meyer G, Schwenn O, Grehn F. Trabeculotomy in congenital glaucoma: comparison to goniotomy. Ophthalmologe. 2000;97:623-628.

16. American Academy of Ophthalmology. Basic and Clinical Science Course Section 10: Glaucoma. San Francisco, CA: American Academy of Opthalmology, 2008-2009:218.

17. Mendicino ME, Lynch MG, Drack A, Beck AD, et al. Long-term surgical and visual outcomes in primary congenital glaucoma: 360 degrees trabeculotomy versus goniotomy. J AAPOS. 2000;4:205-210.

18. Dietlein TS, Jacobi PC, Krieglstein GK. Prognosis of primary ab externo surgery for primary congenital glaucoma. $\mathrm{Br} J$ Ophthalmol. 1999;83:317-322.

19. Akimoto M, Tanihara H, Ngi A, Nagata M. Surgical results of trabeculotomy ab externo for developmental glaucoma. Arch Ophthalmol. 1994;112:1540-1544.

20. Biglan AW, Hiles DA. The visual results following infantile glaucoma surgery. J Pediatr Ophthalmol Strabismus. 1979;16:377-381.

21. Richardson KT, Ferguson WJ, Whaffer RN. Long-term functional results in infantile glaucoma. Trans Am Acad Ophthalmol Otolaryngol. 1967;71:833-837.

22. Ikeda H, Ishigooka H, Muto T, et al. Long-term outcome of trabeculotomy for the treatment of developmental glaucoma. Arch Ophthalmol. 2004;122:1122-1128.

23. Debnath SC, Teichmann KD, Salamah K. Trabeculectomy versus trabeculotomy in congenital glaucoma. Br J Ophthalmol. 1989;73: 608-611.

24. Elder MJ. Combined trabeculotomy-trabeculectomy compared with primary trabeculectomy for congenital glaucoma. Br J Ophthalmol. 1994;78:745-748.

Clinical Ophthalmology

\section{Publish your work in this journal}

Clinical Ophthalmology is an international, peer-reviewed journal covering all subspecialties within ophthalmology. Key topics include: Optometry; Visual science; Pharmacology and drug therapy in eye diseases; Basic Sciences; Primary and Secondary eye care; Patient Safety and Quality of Care Improvements. This journal is indexed on Submit your manuscript here: http://www.dovepress.com/clinical-ophthalmology-journal
25. Mandal AK, Matalia JH, Nutheti R, and Krishnaiah S. Combined trabeculotomy and trabeculectomy in advanced primary developmental glaucoma with corneal diameter of $14 \mathrm{~mm}$ or more. Eye. 2006;20: 135-143.

26. Zhang X, Du S, Fan Q, et al. Long-term surgical outcomes of primary congenital glaucoma in China. Clinics. 2009;64:543-551.

27. Tamcelik N, Ozkiris A. Long-term results of viscotrabeculotomy in congenital glaucoma: comparison to classical trabeculotomy. Br J Ophthalmol. 2008;92:36-39.

28. Mandal AK, Gothwal VK, Bagga H, et al. Outcome of surgery on infants younger than 1 month with congenital glaucoma. Ophthalmology. 2003;110:1909-1915.

29. Mandal AK, Bhatia PG, Bhaskar A, Nutheti R. Long-term surgical and visual outcomes in Indian children with developmental glaucoma operated on within 6 months of birth. Ophthalmology. 2004;111: 283-290.

30. Mandal AK, Gothwal VK, Nutheti R. Surgical outcome of primary developmental glaucoma: a single surgeon's long-term experience from a tertiary eye care centre in India. Eye. 2007;21:764-774.

31. Feusier M, Roy S, Mermoud A. Deep sclerectomy combined with trabeculectomy in pediatric glaucoma. Ophthalmology. 2009;116:30-38.

32. Olsen KE, Huang AS, Wright MM. The efficacy of goniotomy/ trabeculotomy in early-onset glaucoma associated with the Sturge-Weber syndrome. J AAPOS. 1998;2:365-368.

33. Phelps CD. The pathogenesis of glaucoma in Sturge-Weber syndrome. Ophthalmology. 1978;85:276-286.

34. Cibis GW, Tripathi RC, Tripathi BJ. Glaucoma in Sturge-Weber syndrome. Ophthalmology. 1984;91:1061-1071.

35. Burke JP, Bowell R. Primary trabeculectomy in congenital glaucoma. Br J Ophthalmol. 1989;73:186-190.

36. Wagner RS, Caputo AR, Del negro RG, Neigel J. Trabeculectomy with cyclocryotherapy for infantile glaucoma in the Sturge-Weber syndrome. Ann Ophthalmol. 1988;20:289-295.

37. Ali MA, Fahmy IA, Spaeth GL. Trabeculectomy for glaucoma associated with Sturge-Weber syndrome. Ophthal Surg. 1990;21:352-355.

38. Board RJ, Shields MB. Combined trabeculotomy-trabeculectomy for the management of glaucoma associated with Sturge-Weber syndrome. Ophthal Surg. 1981;12:813-817.

39. Agarwal HC, Sandramouli S, Sihota R, Sood NN. Sturge-Weber syndrome: management of glaucoma with combined trabeculotomytrabeculectomy. Ophthal Surg. 1993;24:399-402.

40. Beauchamp GR, Parks MM. Filtering surgery in children: barriers to success. Ophthalmology. 1979;86:170-180.

41. Christensen GR, Records RE. Glaucoma and expulsive hemorrhage mechanisms in the Sturge-Weber syndrome. Ophthalmology. 1979;86: 1360-1366.

42. Elder MJ. Congenital glaucoma in the West Bank and Gaza strip. Br J Ophthalmol. 1993;77:413-416.

43. Yalvac IS, Satana B, Suveren A, et al. Success of trabeculotomy in patients with congenital glaucoma operated on within 3 months of birth. Eye. 2007;21:459-464.

44. Al-Hazmi A, Awad A, Zwaan J, et al. Correlation between surgical success rate and severity of congenital glaucoma. Br J Ophthalmol. 2005;89:449-453.

PubMed Central and CAS, and is the official journal of The Society of Clinical Ophthalmology (SCO). The manuscript management system is completely online and includes a very quick and fair peer-review system, which is all easy to use. Visit http://www.dovepress.com/ testimonials.php to read real quotes from published authors. 